\title{
Evaluation of Heat Recuperation in a Concentric Hydrogen Reduction Reactor
}

\author{
Diane Linne ${ }^{1}$ and Julie Kleinhenz ${ }^{2}$ \\ NASA Glenn Research Center, Cleveland, OH, 44135 \\ and \\ Uday Hegde \\ National Center for Space Exploration Research, Cleveland, OH, 44135
}

\begin{abstract}
Heat recuperation in an ISRU reactor system involves the recovery of heat from a reacted regolith batch by transferring this energy into a batch of fresh regolith. One concept for a hydrogen reduction reactor is a concentric chamber design where heat is transferred from the inner, reaction chamber into fresh regolith in the outer, recuperation chamber. This concept was tested and analyzed to define the overall benefit compared to a more traditional single chamber batch reactor. Data was gathered for heat-up and recuperation in the inner chamber alone, simulating a single chamber design, as well as recuperation into the outer chamber, simulating a dual chamber design. Experimental data was also used to improve two analytical models, with good agreement for temperature behavior during recuperation, calculated mass of the reactor concepts, and energy required during heat-up. The five tests, performed using JSC-1A regolith simulant, also explored the effectiveness of helium gas fluidization, hydrogen gas fluidization, and vibrational fluidization. Results indicate that higher hydrogen volumetric flow rates are required compared to helium for complete fluidization and mixing, and that vibrational fluidization may provide equivalent mixing while eliminating the need to flow large amounts of excess hydrogen. Analysis of the total energy required for heat-up and steady-state operations for a variety of conditions and assumptions shows that the dual-chamber concept requires the same or more energy than the single chamber concept. With no clear energy savings, the added mass and complexity of the dual-chamber makes it unlikely that this design concept will provide any added benefit to the overall ISRU oxygen production system.
\end{abstract}

\section{Introduction}

L EARNING to live off the land through in-situ resource utilization (ISRU) is a leading candidate for reducing the delivery of consumables from Earth for exploration missions to the moon, Mars, and other destinations. One concept for extracting oxygen from the lunar regolith is to use hydrogen to reduce iron oxides, resulting in the formation of water for subsequent recovery of oxygen and hydrogen. The hydrogen reduction reaction takes place at $900-1100{ }^{\circ} \mathrm{C}$, and typical yields are between 1 and 3 mass percent of the regolith in each batch..$^{1-3}$ While this process is considered the most advanced of the options being investigated because of the relatively low temperatures, the low yield results in high power requirements to heat-up large amounts of regolith that will ultimately be discarded. Several concepts have been proposed to recuperate the heat from the spent regolith by transferring it to the incoming cold regolith before disposal. Previous work investigated the effectiveness of heat recuperation in a dual-chamber reactor design, measuring the temperature rise in a fresh batch of simulant placed in the outer chamber after the simulant and walls of the inner chamber had reached $750{ }^{\circ} \mathrm{C} .{ }^{4}$

One key observation from the previous work was that the majority of the heat recuperation came not from the hot regolith in the inner chamber, but from the hot reactor walls that represent a significant thermal mass. It was also observed that the dual-chamber hardware required significantly more energy to heat the regolith to operating

\footnotetext{
${ }^{1}$ Senior Research Engineer, Propellants and Propulsion Branch, MS 301-3, AIAA Associate Fellow.

${ }^{2}$ Research Engineer, Propellants and Propulsion Branch, MS 301-3, AIAA Senior Member.

${ }^{3}$ Principal Researcher, MS 110-3, AIAA Associate Fellow.
}

American Institute of Aeronautics and Astronautics 
temperature than theory for idealized operation predicts due to the added thermal mass and large external surface area through which heat is lost to the environment. These two observations raised the question of whether a traditional single chamber reactor might be able to pre-heat each fresh regolith batch through recuperation of stored energy in the chamber walls, while providing less of a thermal sink during heat-up and reduced heat loss due to its smaller external surface area. While resources were not available to build a mock-up of a single chamber reactor, the dual chamber hardware could be operated as a single chamber to gather sufficient data to evaluate and compare the total energy requirements of the single and dual-chamber design concepts. Additional data also allowed comparisons of helium gas fluidization, hydrogen gas fluidization, and vibrational fluidization methods.

\section{Experimental Hardware and Procedures}

The reactor vessel used to obtain experimental data was modeled after a design prototype from NASA Johnson Space Center (JSC). The soil is held in two separate, concentric chambers. The reaction portion of the test, where the soil is heated to $1000^{\circ} \mathrm{C}$ in the presence of hydrogen gas flow, takes place in the inner chamber. Once reaction is complete, fresh soil is filled into the outer chamber where it will absorb, or recuperate, heat from the inner chamber. The chamber dimensions for the GRC hardware matched that of the JSC design to enable immediate feedback for design iterations. ${ }^{4}$ A schematic of the hardware is shown in Fig. 1. The silicon carbide heater, located at the center of the inner chamber, has a maximum temperature rating of $1370{ }^{\circ} \mathrm{C}$ in a hydrogen environment. The heating element is wrapped in a thin silica sleeve and contained in a stainless steel shroud to protect it from soil contamination. Flow enters both chambers through a sintered metal plate at the base of the reactor and can be isolated between the two chambers. Flow can also be directed through gas nozzles which are oriented tangentially to the chamber diameter to create a swirling motion. Soil is manually filled and removed from the chambers via ports at the top and bottom of the vessel. Each chamber is intended to hold $10 \mathrm{~kg}$ of JSC-1A lunar soil simulant. The entire assembly can be vibrated using a $3000 \mathrm{rpm}$ pneumatic motor. The maximum amplitude of the vibration was 3 $\mathrm{mm}$. Figure 2 shows the hardware on the test stand.
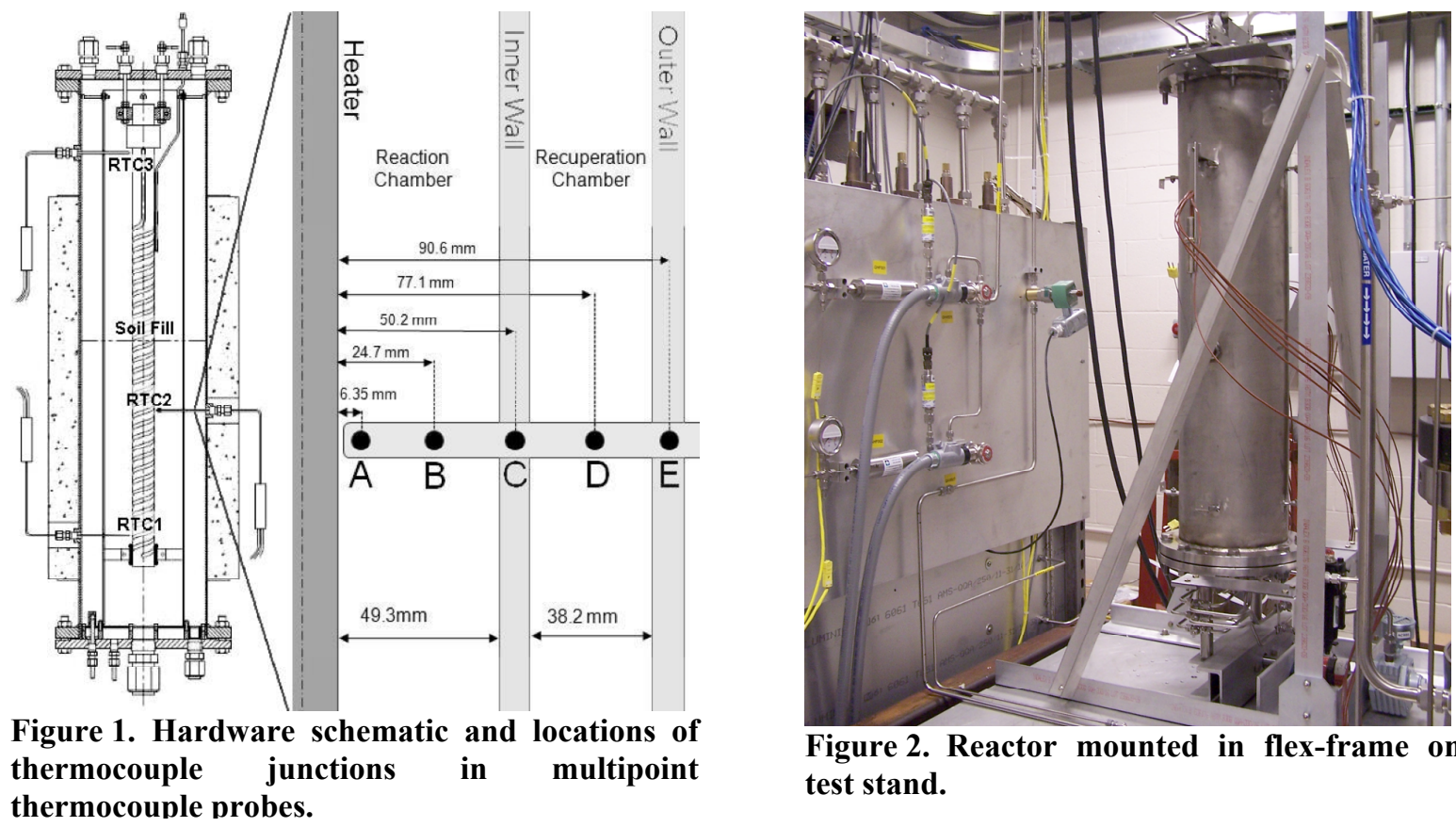

Figure 2. Reactor mounted in flex-frame on test stand.

Three multipoint thermocouple probes were the primary data measurement. Each thermocouple probe housed five radially distributed thermocouple junctions, shown in Fig.1. Two probes (RTC1 and RTC2) were nominally located below the soil level, while the top probe (RTC3) was exposed.

The goal of this test series was to evaluate the effectiveness of the recuperation reactor design. Thus, the dual chamber reactor design was traded against a more traditional single chamber reactor. The operation scenarios of the two are as follows: 
Single chamber reactor: Soil would be heated to $1000{ }^{\circ} \mathrm{C}$ within the reactor chamber. Once the hydrogen reduction reaction is completed, the reacted soil would be removed from the chamber. A fresh soil batch would then be added to the hot chamber. Heat absorbed by the soil from the chamber walls could reduce the total heating time. This type of heat recuperation was evaluated using only the inner chamber of the existing reactor. Soil was added to a preheated empty chamber and allowed to recuperate heat from the warm reactor walls with the aid of fluidization.

Dual chamber reactor: The soil would be heated and reacted within the inner chamber. Once the reaction is completed, fresh soil would be added to the outer chamber. Heat from the reacted soil in the inner chamber would be transferred into the soil in the outer chamber. Thus, the fresh soil would recuperate heat from the reacted soil with the aid of fluidization. The inner chamber would then be emptied, and the pre-heated soil from the outer chamber would be transferred into the inner reaction chamber. The hydrogen reduction reaction would take place, and the cycle repeated. Only the recuperation portion of this test was evaluated experimentally.

Both scenarios were accomplished in a single test. First, the empty reactor (no soil in either chamber) was heated up to achieve a wall temperature of around $700^{\circ} \mathrm{C}$ (maximum operational temperature). The heater was then deactivated, and soil was added to the inner chamber. This soil was allowed to recuperate heat from the chamber walls using gas and/or vibrational fluidization to improve mixing, thus simulating a single chamber recuperation. Once the soil temperature reached a peak value, the heater was then activated to enter the 'heat-up' segment of the test. The soil was heated to $1000{ }^{\circ} \mathrm{C}$, or until the outer wall temperature reached its maximum allowable operating temperature, whichever came first. Gas fluidization was used to improve heat transfer during the heat-up. In an actual reactor, this operating temperature would be maintained for 1 to 2 hours while the oxygen is extracted in the form of water. However, in these tests the reaction phase was skipped and the heater was deactivated as if the reaction cycle was complete. Soil was then added to the outer chamber. Using gas fluidization in both chambers, the soil in the outer chamber recuperated heat from the soil in the inner chamber and the vessel walls.

Table I summarizes the five tests performed in this series. The first three tests were used for analytical model evaluation. The last two tests were intended to demonstrate vibrational fluidization effectiveness during all three test segments. However, difficulties with electrical connections during vibration made the heater inoperable, thus only the single chamber recuperation was demonstrated. In all tests, the gas flow rate was pulsed, $0.5 \mathrm{~s}$ on, $0.5 \mathrm{~s}$ off. This method demonstrated good

Table I. Summary of tests conditions in this test series.

\begin{tabular}{|c|l|c|c|}
\hline Test \# & \multicolumn{1}{|c|}{ Test Phase } & $\begin{array}{c}\text { Fluidizing Gas and } \\
\text { Flow Rate }\end{array}$ & $\begin{array}{c}\text { Vibrational } \\
\text { Fluidization }\end{array}$ \\
\hline 11 & $\begin{array}{l}\text { Single chamber recuperation } \\
\text { Heat-up } \\
\text { Dual chamber recuperation }\end{array}$ & Helium, 40 slpm & none \\
\hline 12 & $\begin{array}{l}\text { Single chamber recuperation } \\
\text { Heat-up } \\
\text { Dual chamber recuperation }\end{array}$ & Hydrogen, 55 slpm & none \\
\hline 13 & $\begin{array}{l}\text { Single chamber recuperation } \\
\text { Heat-up } \\
\text { Dual chamber recuperation }\end{array}$ & Hydrogen, 40 slpm & none \\
\hline 14 & Single chamber recuperation & Helium, 10 slpm & $4 \mathrm{~g}$ \\
\hline 15 & Single chamber recuperation & Helium, 15 slpm & $2.5-4 \mathrm{~g}$ \\
\hline
\end{tabular}
fluidization during tests at JSC. The flow rates stated below are the averaged pulsed flow rates.

\section{Results}

The temperature with time traces for thermocouple probes 1 and 2 are shown in Fig. 3 for the baseline case with helium gas fluidization. Also shown are the power and averaged flow rate. Heating of the empty reactor took place from time 0 to approximately 60 minutes, followed by recuperation in the inner chamber ( 60 to $\sim 84$ mins), heat-up of the regolith in the inner chamber ( 84 to $\sim 200$ minutes), and finally recuperation in the outer chamber. A detailed discussion of the temperature behaviors during different phases of the test can be found in Ref. 4. In general, the relatively small spread in temperature at location A (near the heater), B (middle of the regolith), and C (inner chamber wall) during heat-up ( 84 to 200 mins) indicates good radial mixing. The relatively similar temperatures at a given radial location, such as location B, for the upper and lower probes (RTC2 and RTC1) indicates good axial mixing. During both recuperation phases, there is an initial drop in temperatures when the cold simulant is poured into the chamber. The regolith temperature (location B for the first recuperation, and location D for the second 
recuperation) begins to increase slowly immediately after the probe is covered, and then experiences a higher rate of temperature increase when the flow is turned on and mixing is increased.

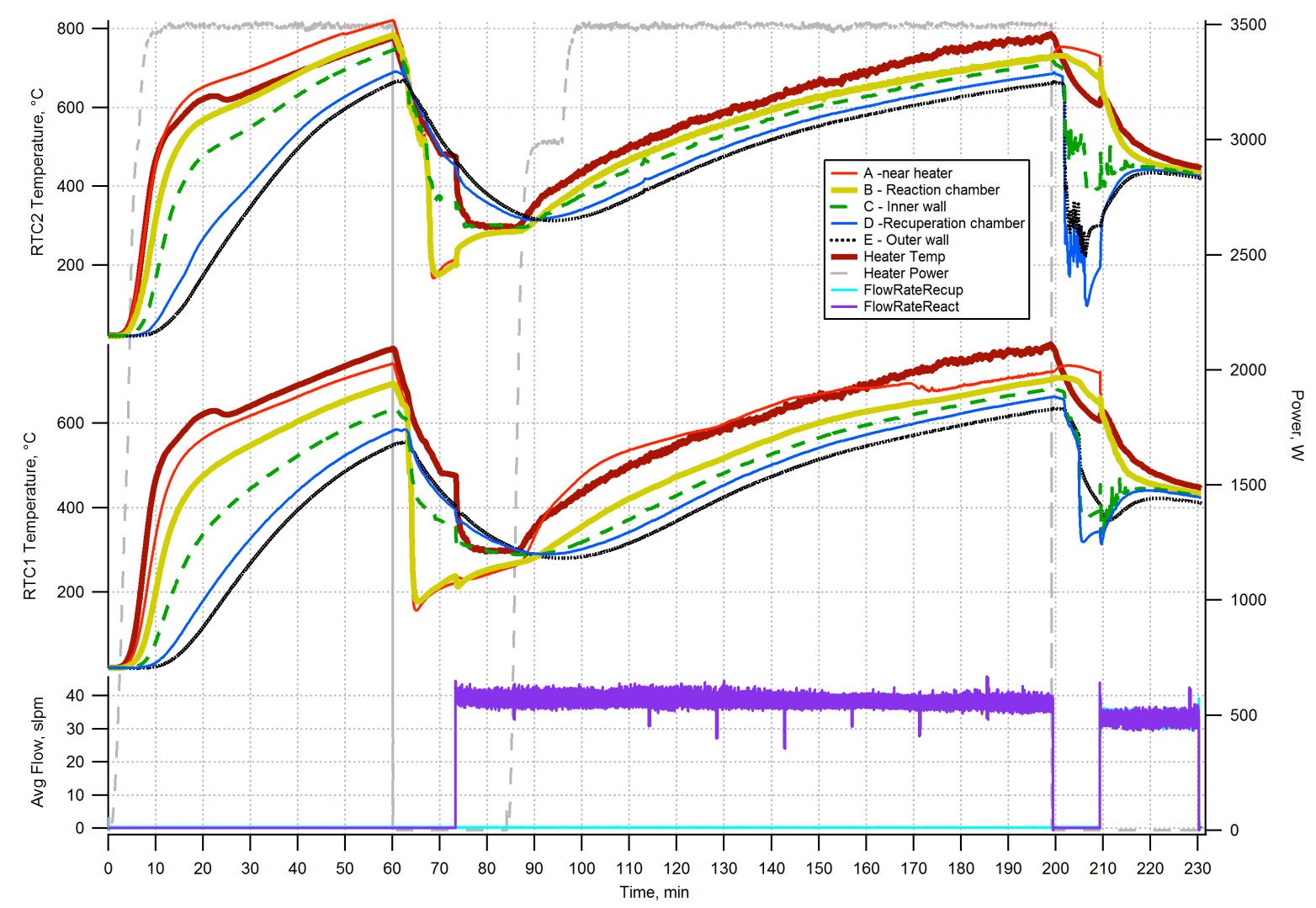

Figure 3. Temperature traces for Test 11 baseline case.

\section{A. Fluidization Effects}

Vibrational fluidization has been used in previous ISRU reactor systems as an effective alternative to gas fluidization. ${ }^{5}$ However, the previous reactors were small scale ( $100 \mathrm{~g}$ of simulant). The current reactor is the first large scale (10 kg of simulant) reactor to employ vibration. Since the vibrational capability was an add-on to an existing reactor design, compatibility issues complicated this testing. Numerous precautions were taken to ruggedize the ceramic heater against vibration, which ultimately were successful in protecting the heating element. However, the heater lost power within 5 minutes of vibration start in both tests. Evidence of arcing near the power connector suggests an electrical issue.

Despite the heater shutdown, vibrational fluidization data was obtained for the single chamber recuperation test. Figure 4 shows a comparison of this recuperation period for tests with and without vibration. For the gas fluidization case (from Test 11), helium was pulsed at $80 \mathrm{slpm}$ maximum for an averaged flow of $40 \mathrm{slpm}$. The vibration case was supplemented by an averaged helium gas flow of $15 \mathrm{slpm}$, which mimics the flow of hydrogen needed to sustain a hydrogen reduction reaction, but is insufficient to fluidize. The vibration level was set at $4 \mathrm{~g}$ but shifted to $2.5 \mathrm{~g}$ by the end of the test. In the figure, time $=0$ is the point at which flow was initiated. Vibration was ramped up over 1 to 2 minutes following the start of flow. The low temperatures and short time scale diminish the effects somewhat, but it is evident that the temperatures converge more quickly in the vibration case.

A comparison was also performed to examine the effect of gas type on fluidization effectiveness. Identical tests were performed with helium and hydrogen gas fluidization. The averaged pulsed flow rate in both tests was $40 \mathrm{slpm}$. The effect of gas type during the recuperation period could not be ascertained. Since most of the heat exchange occurs when the soil is added to the chamber, the recuperation periods are short, around $10 \mathrm{~min}$. Additionally, the chamber must be purged with helium prior to hydrogen flow initiation for safety precautions, which consumes nearly half of the recuperation period. However, the effect of gas type can be seen during the soil heat-up period 


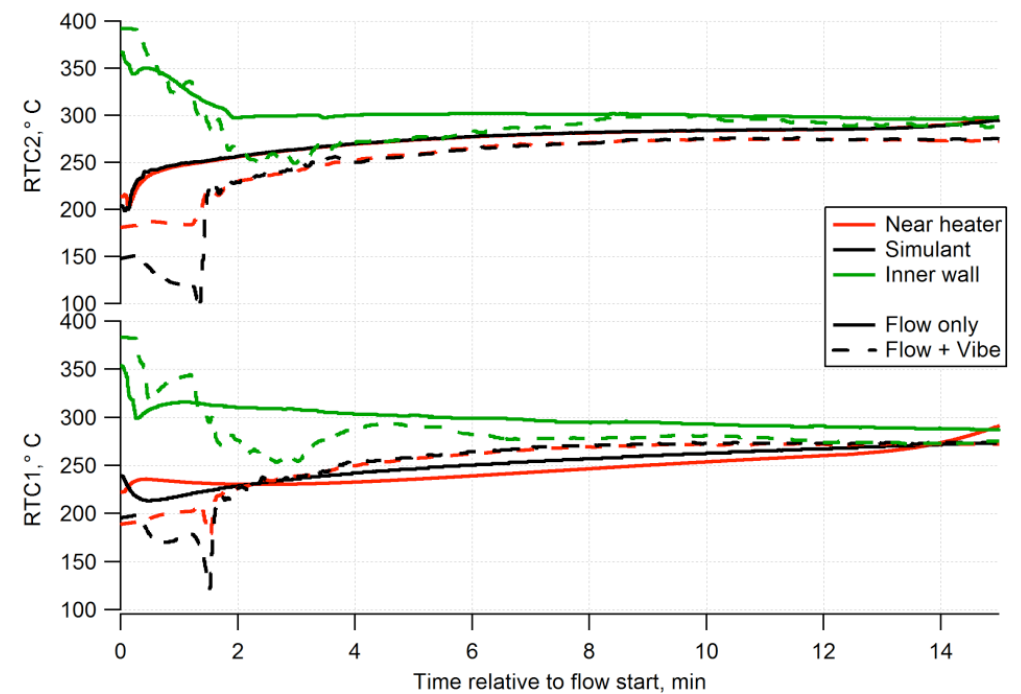

Figure 4. Comparison of heat recuperation in the inner chamber with gas fluidization (Test 11) and vibrational fluidization (Test 15). (when the heater is active). Figure 5 shows this portion of the test. The thermocouple traces from the probe near the bed surface (RTC2) and the lower probe (RTC1) are shown, along with the average flow rates. For both temperature probes, the hydrogen temperatures near the heater are higher, by about $30{ }^{\circ} \mathrm{C}$ in probe 2 , and as much as $100{ }^{\circ} \mathrm{C}$ in probe 1 . Likewise the temperature distribution in probe 1 is markedly wider for the hydrogen fluidization, indicating less effective mixing and therefore poorer heat transfer. Classical fluidization theory shows the minimum gas fluidization velocity dependent on the gas viscosity; the lower viscosity of the hydrogen should therefore require higher

inlet velocities to achieve good fluidization and thermal mixing, consistent with the experimental observations.

\section{B. Analytical Model}

An analytical model, discussed in detail in Ref. 4, was created to evaluate the effective heat transfer coefficient during the recuperation portion of the tests. The model evaluates temperature as a function of time in four zones moving radially out from the central heater. For recuperation in the outer chamber, zone 1 is the hot regolith in the inner chamber and the inner chamber wall, zone 2 is the regolith in the outer chamber, zone 3 is the outer chamber wall, and zone 4 is the

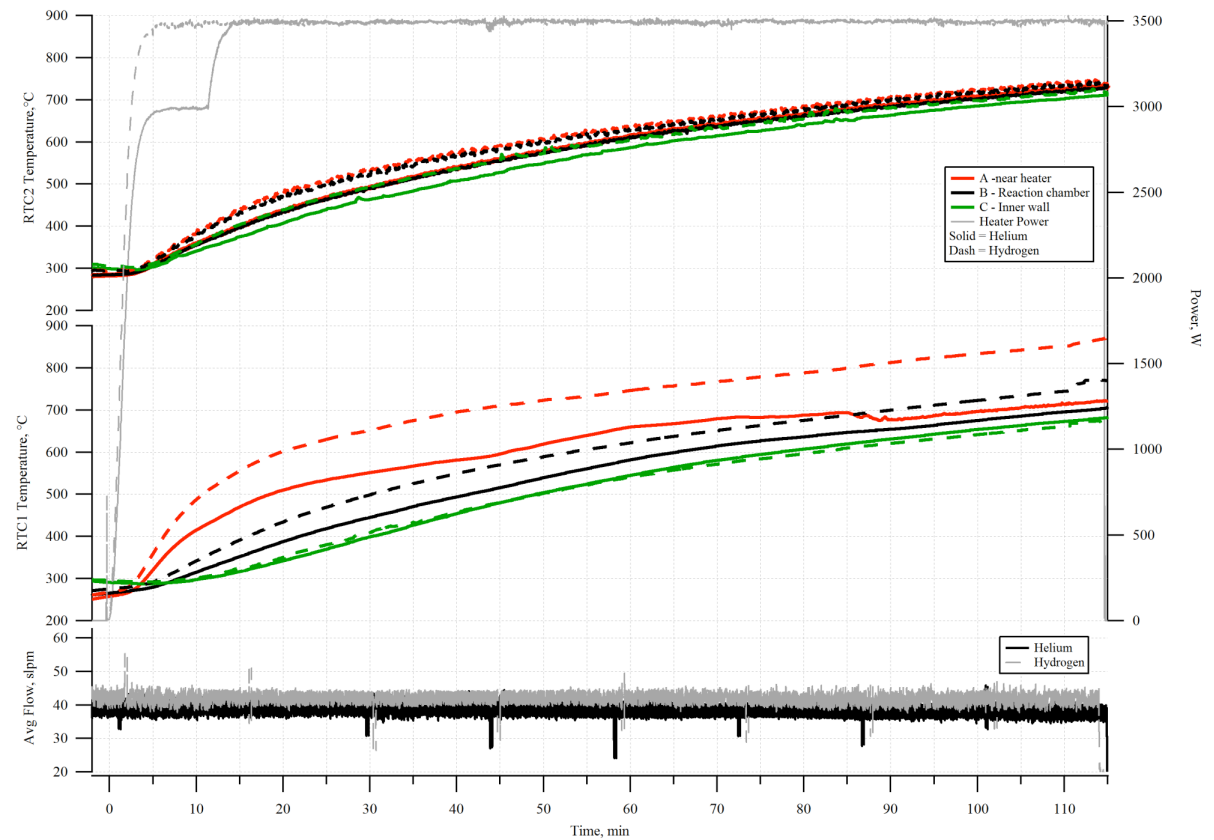

Figure 5. Comparison of mixing during heat-up for helium fluidization and hydrogen fluidization.

insulation. For

recuperation in the inner chamber when there is no regolith in the outer chamber, zone 1 is the regolith in the inner chamber, zone 2 is the inner chamber wall, zone 3 is the helium gas in the outer chamber, and zone 4 is a composite of the outer chamber wall and insulation. The effective thermal conductivity is adjusted in the model until the time to reach peak temperature matches the experiment. This parameter is used to evaluate the relative effectiveness of the different fluidization methods. 
Figure 6 shows the model and experimental data from the recuperation period in Test 11 (first recuperation) and Test 15 in an effort to compare the vibrofluidization with the helium gas fluidization. In both tests 11 and 15 , the model predicts well the increase in temperature of the regolith in the inner chamber along with the simultaneous decrease in wall temperature as thermal energy is transferred from the chamber wall to the regolith. Controlled measurements of the thermal conductivity of JSC-1A simulant in air (static conditions) determined an effective thermal conductivity between 0.2 and $0.3 \mathrm{~W} / \mathrm{m}-\mathrm{K}$ at atmospheric pressure. ${ }^{6}$ Values for effective thermal conductivity during the recuperation tests with both gas fluidization and vibrofluidization needed to be increased an order-of-magnitude over this value to achieve the match to data shown in the figure. There was no significant difference in apparent effective thermal conductivity between the gas fluidization and the vibrofluidization cases. However, the hydrogen flow rate required for gas fluidization in a full-scale reactor is significantly larger than the flow required for efficient hydrogen reduction processing, and this excess gas flow will continually 'steal' energy from the chamber and increase the size and power of downstream gas processing components. Therefore, while the vibrofluidization method indicated only minimal thermal mixing benefits during the recuperation and heat-up phases, the ability to operate with lower hydrogen flow rates may provide an overall system benefit that merits further investigation.
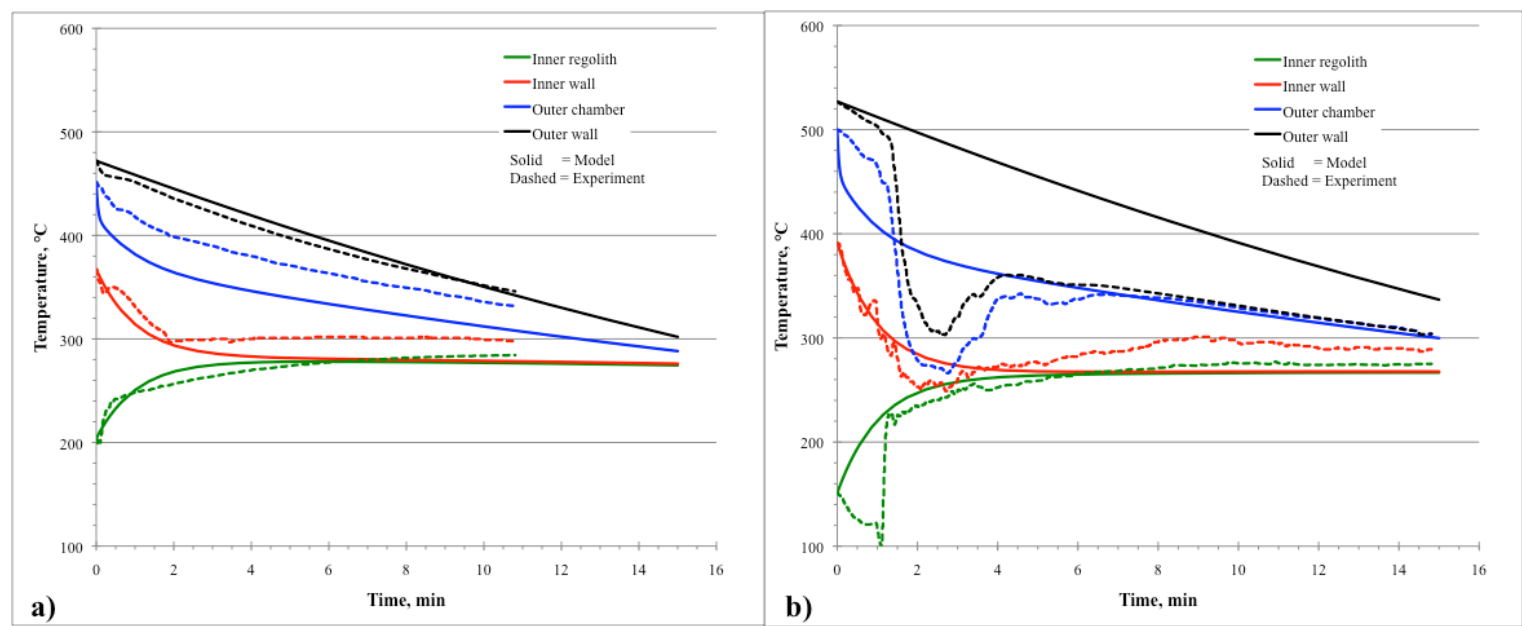

Figure 6. Comparison of heat recuperation in the inner chamber for a) helium gas fluidization (Test 11) and b) vibrational fluidization (Test 15).

The low mass of the gas in the outer chamber makes the model's zone 3 more sensitive to small errors in assumed heat transfer coefficients, but the model prediction for temperature in the outer chamber wall shows a good match to the general trend of the data. The temperature decline of the outer wall is predominantly driven by heat loss to the environment through natural convection, and for Test 11 the model shows an excellent correlation to the data. The erratic behavior of the outer chamber regolith and outer wall temperatures during the first 5 minutes of Test 15 could be an indication of inconsistent mixing of cooler and hotter regolith in the outer annular chamber.

The analytical model was also used to describe the behavior of the second recuperation phase (outer chamber recuperation) in Test 11 where regolith in the outer chamber absorbs energy from both the inner chamber regolith and the chamber walls (Fig. 7). The model again

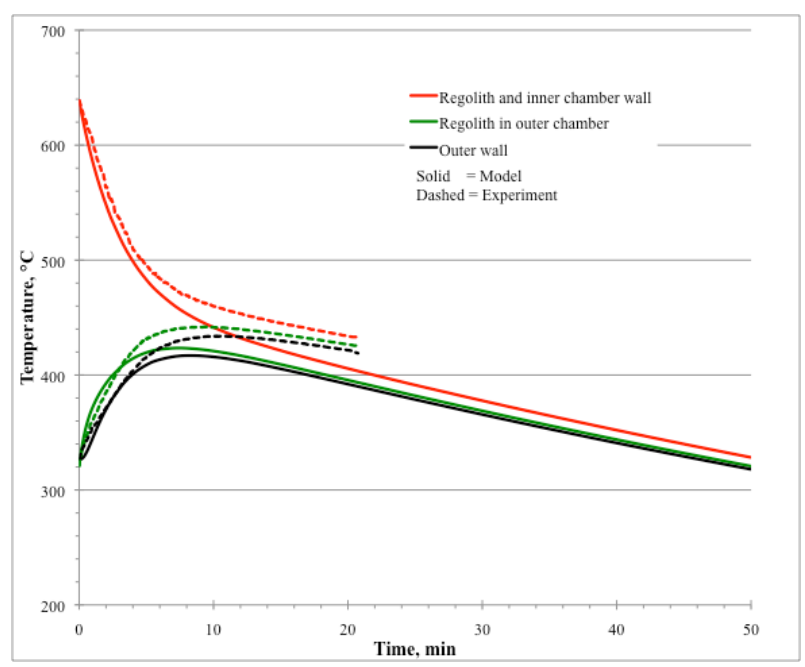

Figure 7. Heat recuperation experimental and model predictions for outer chamber recuperation (Test 11). 
shows good correlation with the experimental data. As discussed in Ref. 4, during design of the dual-chamber reactor it was assumed that the outer wall would not reach temperatures as high as the inner reaction chamber, and therefore the outer shell pressure vessel was designed for a maximum operating temperature of $700{ }^{\circ} \mathrm{C}$. However, the heat loss out of the inner chamber turned out to be significant, thus slowing down the temperature rise and resulting in more uniform hardware temperatures. The outer wall temperatures tended to lag the inner chamber temperatures by only around $100{ }^{\circ} \mathrm{C}$; this limited the maximum temperature that could be obtained in these tests. Therefore, to perform an energy balance comparison of a dual-chamber reactor and a single chamber reactor under actual desired operating conditions (temperature of reaction of $1000{ }^{\circ} \mathrm{C}$ ), the analytical model validated here at the lower temperatures was used to predict temperatures after recuperation for both options.

\section{Energy Balance}

The intent of the dual-chamber design was to reduce the overall power requirements of a hydrogen reduction insitu production plant by recuperating some of the heat energy from a spent (reacted) batch of regolith before discharging it back into the lunar environment. However, it was clear from the first test of the dual-chamber hardware that the significant additional thermal mass of the outer chamber and larger top and bottom caps required additional energy to bring the regolith and structure up to operating temperature. In addition, the larger surface area of the second outer chamber increases the heat loss to the environment through convection and radiation. Therefore, in order to fully evaluate the potential benefits of the concept, an overall energy balance was performed.

Before the analytical model could be used to calculate temperatures after a heat recuperation cycle, the initial conditions at the start of a recuperation cycle needed to be determined. For a dual chamber, it was assumed that the regolith in the inner chamber and the inner chamber wall temperatures are both at the reaction temperature of 1000 ${ }^{\circ} \mathrm{C}$. From the experimental tests, the outer wall temperature lags the inner wall temperature by around $100{ }^{\circ} \mathrm{C}$, so it would be at $900{ }^{\circ} \mathrm{C}$ at the end of a batch processing cycle. From the data (Fig. 3), the outer wall temperature drops 200 to $300{ }^{\circ} \mathrm{C}$ when the cold regolith is added to the outer chamber, while the regolith picks up about $100{ }^{\circ} \mathrm{C}$ from the hot walls as it is loaded into the outer chamber. Therefore, it was assumed that the outer wall temperature is 700 ${ }^{\circ} \mathrm{C}$ and the outer chamber regolith is at $127{ }^{\circ} \mathrm{C}$ at the start of the fluidized recuperation phase. For the single chamber, it was assumed that the chamber wall loses $200{ }^{\circ} \mathrm{C}$ from its peak of $1000{ }^{\circ} \mathrm{C}$ during the loading of the regolith, and the regolith picks up $100^{\circ} \mathrm{C}$. The starting conditions for the recuperation phase for the single and dual chamber designs are summarized in Table II. Using these initial conditions, the recuperation phase for each concept was modeled and the results are shown in Fig. 8. Ten kilograms of simulant was assumed in both chambers. For the

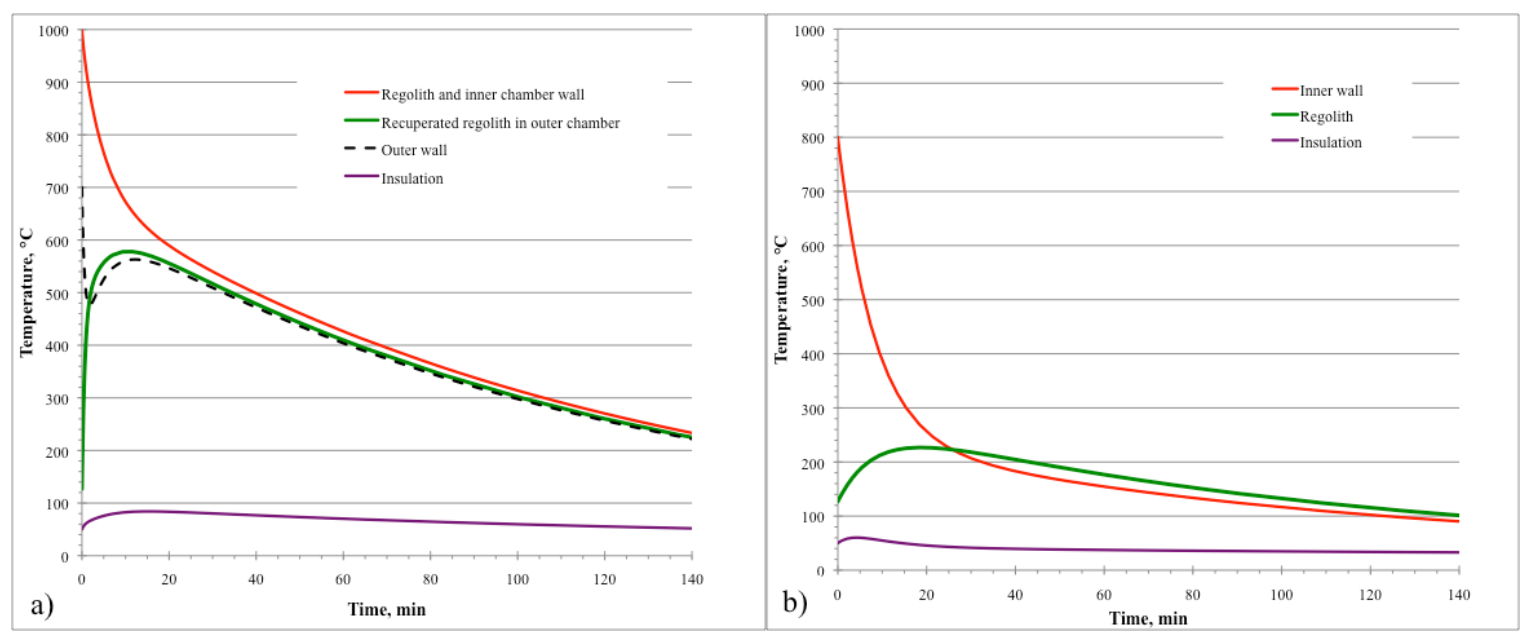

Figure 8 - Heat recuperation analytical predictions for a) dual-chamber design, and b) single chamber.

dual-chamber (Fig. 8a), the regolith in the outer chamber reaches a peak of approximately $575{ }^{\circ} \mathrm{C}$ after 10 minutes, with the outer wall slightly cooler at $555{ }^{\circ} \mathrm{C}$. The spent regolith in the inner chamber would now have to be removed, and the pre-heated fresh regolith in the outer chamber transferred to the inner chamber for reaction. While it is likely that the regolith temperature will drop during the transfer process, this thermal process was not modeled here. Therefore the regolith and outer wall temperatures at the end of the recuperation phase were used for the regolith now in the inner chamber. The inner wall temperature was assumed to come down another $100{ }^{\circ} \mathrm{C}$ and equilibrate with the regolith. The heater would then be activated to bring this preheated soil to reaction temperature. 
For the single-chamber concept (Fig. 8b), the regolith warms up to only $225^{\circ} \mathrm{C}$ while the wall temperature drops to $300{ }^{\circ} \mathrm{C}$. In this case, the heater can be turned on as soon as regolith temperature has peaked (or sooner if desired), and therefore the wall temperature was assumed to stay at the $300{ }^{\circ} \mathrm{C}$. These temperatures are summarized in Table III and were used as the starting conditions for the next heat-up phase.

Table II. Initial conditions before heat recuperation.

\begin{tabular}{|l|c|c|}
\hline \multirow{2}{*}{} & \multicolumn{2}{|c|}{ Temperature, ${ }^{\circ} \mathbf{C}$} \\
\cline { 2 - 3 } & $\begin{array}{c}\text { Dual } \\
\text { Chamber }\end{array}$ & $\begin{array}{c}\text { Single } \\
\text { Chamber }\end{array}$ \\
\hline Regolith, inner chamber & 1000 & 127 \\
Inner wall & 1000 & 800 \\
Regolith, outer chamber & 127 & N/A \\
Outer wall & 700 & N/A \\
\hline
\end{tabular}

Table III. Conditions after heat recuperation and before next heat-up cycle.

\begin{tabular}{|l|c|c|}
\hline \multirow{2}{*}{} & \multicolumn{2}{|c|}{ Temperature, ${ }^{\circ} \mathbf{C}$} \\
\cline { 2 - 3 } & $\begin{array}{c}\text { Dual } \\
\text { Chamber }\end{array}$ & $\begin{array}{c}\text { Single } \\
\text { Chamber }\end{array}$ \\
\hline Regolith, inner chamber & 575 & 225 \\
Inner wall & 575 & 300 \\
Outer wall & 555 & N/A \\
\hline
\end{tabular}

An analytical model of the hydrogen reduction reactor ${ }^{7}$ was used to determine the energy required to heat-up the regolith and chamber(s) for various starting conditions. While the emphasis of this model has been on high-fidelity predictions of the chemical reaction rates and oxygen yields, it also includes subroutines for calculation of reactor mass and the energy required to heat-up and maintain temperature. However, several modifications were made to improve the fidelity of both the mass and the power calculations.

An option was added in the input list of the hydrogen reduction reactor model to indicate whether the reactor is a single- or dual-chamber design. For a dual-chamber, the inner chamber diameter is specified, and the annular gap is calculated such that the height of the simulant in the outer chamber is the same as the inner chamber. The hydrogen reduction reactor model has an option for either fluidized bed, mechanically well-stirred, or loosely-packed bed. If the fluidized-bed option is selected, the height of the reactor is calculated based on the transport disengagement height, which is typically three times the height of the stationary simulant bed. Cold flow visualizations performed at NASA JSC indicated that a much shorter free height was required for the pulsed-flow fluidization method, and their reactor was designed with the free space equal to the stationary bed height. The mechanically well-stirred reactor option in the model was used here as it allows for more user-control of the total reactor height, which was set here at twice the bed height to best match the actual hardware design. The thickness of the reactor walls for any reactor design is calculated based on the hoop stress at operating pressure and temperature and the allowable stress at temperature of the chosen material, with a safety factor of 3.5 as recommended in the ASME Boiler and Pressure Vessel Code (BPV). ${ }^{8}$

For the top and bottom caps, the design methodology from the BPV is followed for bolted flange connections with ring type gaskets and unstayed flat heads and covers. While the inner diameter of the flange is matched to the diameter of the outermost chamber shell, the flange thickness is held constant at that used in the dual-chamber hardware, as there is a minimum width needed for the seal and bolt circle, regardless of inner diameter. The modified reactor model was run to calculate reactor mass at the operating pressure (50 psia) and temperature (1000 ${ }^{\circ} \mathrm{C}$ ) and the allowable stress at temperature of Inconel 625 that was used in the design of the test hardware. The results for the inner chamber wall, outer chamber wall, top and bottom flange, and top and bottom flathead cap compared well to the mass of the actual hardware (Table IV).

The hydrogen reduction reactor model was originally written for the lunar environment, and includes a term for heat loss due to radiation. For operation in the ambient environment, a convective loss term was added to the model. Due to the excellent matching of the outer wall temperature profile from the recuperation thermal model, the same convective loss correlation (Churchill-Thelen) used in that model was added to the reactor model. This convective heat

Table IV. Comparison of model-calculated reactor masses to actual hardware masses.

\begin{tabular}{|l|c|c|}
\hline \multirow{2}{*}{} & \multicolumn{2}{|c|}{ Mass, kg } \\
\cline { 2 - 3 } & Model & Actual \\
\hline Wall, inner chamber & 6.6 & 4.5 \\
Wall, outer chamber & 13.6 & 16.3 \\
Flange (2) & 9.4 & 10.8 \\
Flathead (2) & 16.8 & 19.0 \\
\hline \hline Total & 46.4 & 50.6 \\
\hline
\end{tabular}
loss is only a few hundred watts at cold wall temperatures but climbs to over $2 \mathrm{~kW}$ at hot wall temperatures, even with 2 inches of a ceramic felt blanket insulation. It was observed during the experimental tests that the heating of the regolith simulant was not linear with time (Fig. 3), and this was caused by the increasing heat loss as the outer wall temperature increased. Therefore, the 
energy algorithms in the reactor model were structured such that the simulant temperature is increased in five steps to mimic the continuous transient heating, with the fraction of time at each temperature step based on the relative magnitude of the heat loss term in that temperature range. The total energy required to heat the reactor and simulant is then calculated by adding the total heat loss over time to the energy required to raise the temperature of the thermal mass of the simulant, inner chamber wall, outer chamber wall, and flanges and flatheads. Based on experimental observations, the temperature of the flanges and flatheads was assumed to be one-third the temperature of the outer chamber wall. Convective loss out the top and bottom flatheads was not included in these calculations.

The calculated energy results from the model were compared to actual test conditions and these are summarized in Table V. Three test conditions were used for these comparisons. The second heat-up cycle in Test 11 (Fig. 3) was the simplest in terms of energy input; the heater power was set to $3.5 \mathrm{~kW}$ at the start and held constant for the entire heat-up cycle. Because a single chamber heat-up and recuperation cycle of the inner chamber had been run at the start of Test 11, the initial temperatures for this comparison started at 285 to $335^{\circ} \mathrm{C}$. The single chamber heat-up cycle in Test 11 was also used for a comparison. If the model is run with no simulant mass it will calculate a zeroheight (and mass) chamber. Therefore, the model was run with $10 \mathrm{~kg}$ of simulant in the chamber with the specific heat set to a near-zero value to effectively eliminate its thermal mass. It is clear from Fig. 3 that the helium gas in the empty inner chamber acted as a low level insulator between the heater and the reactor walls, thus slowing down the heat transfer to the outer chamber wall. This resulted in a more linear temperature rise than is seen for tests where

Table V. Comparison of model-predicted energy requirements to experimental.

\begin{tabular}{|l|c|c|c|}
\hline & $\begin{array}{c}\text { Test 11, 2nd } \\
\text { heat-up cycle }\end{array}$ & $\begin{array}{c}\text { Test 11, 1st } \\
\text { heat-up cycle }\end{array}$ & Test 3 \\
\hline Initial temperatures, ${ }^{\circ} \mathrm{C}$ & & & \\
$\quad$ Regolith & 285 & N/A & 32 \\
$\quad$ Inner wall & 297 & 22 & 31 \\
$\quad$ Outer wall & 335 & 20 & 21 \\
\hline Final temperatures, ${ }^{\circ} \mathrm{C}$ & & & \\
$\quad$ Regolith & 727 & $\mathrm{~N} / \mathrm{A}$ & 690 \\
$\quad$ Inner wall & 711 & 745 & 685 \\
$\quad$ Outer wall & 661 & 662 & 638 \\
\hline Total time, min & 113 & 56 & 137 \\
\hline Ave Power, $\mathrm{kW}$ & 3.46 & 3.42 & 3.27 \\
Model Predicted Power, $\mathrm{kW}$ & 2.92 & $3.30^{*}$ & 3.02 \\
\hline
\end{tabular}

*linear temperature-time steps used the chamber is filled, and the model was adjusted for this comparison to assume a linear temperature increase instead of one pro-rated based on the convective heatloss as discussed above. Finally, data from the heat-up cycle from Test 3, presented in Ref. 4, was used to represent a case where the chamber was filled with regolith and the initial temperatures were cold. For all three comparisons, the model under-predicts the total energy required by 4 to 16 percent. Considering the many assumptions and approximations that went into the analysis, the ability of the model to predict the energy requirements was considered sufficient to proceed with an evaluation of the overall energy balance for the single- and dual-chamber concepts.

The modified hydrogen reduction reactor model was used to calculate the energy required to heat-up a single chamber and a dual chamber to $1000{ }^{\circ} \mathrm{C}$ regolith temperatures from the starting temperatures listed in Table III. This would be the repeated power required to perform long-term operations of a production plant. The heat-up time was arbitrarily set at 1 hour for the initial assessment. The single chamber has a much smaller surface area exposed to the environment than the dual chamber and therefore less convective and radiative losses. The single chamber also has about half of the metal mass of the dual chamber, and therefore soaks up less energy on each cycle for every 100 degrees that the regolith and walls are heated. However, the larger thermal mass of the dual-chamber design, together with the ability to recuperate energy from the previous batch of regolith means that the fresh regolith in the dual chamber reactor starts at a higher temperature (see Table III). In spite of this advantage, the dual-chamber requires approximately 17 percent more energy to bring the regolith up to $1000^{\circ} \mathrm{C}$ than the single chamber $(5.1 \mathrm{~kW}$ compared to $4.3 \mathrm{~kW}$ for a $1-\mathrm{hr}$ heat-up time). The model also calculates radiative losses during steady-state reaction temperatures. While this portion of the model has not been validated with experiments, it predicts that the dualchamber design requires 25 percent more power to maintain operating temperature than the single chamber $(1.0 \mathrm{~kW}$ compared to $0.8 \mathrm{~kW}$ for the reactor size and conditions evaluated here). Previous system analysis of the overall ISRU production plant has determined that there is an overall mass and power savings if the plant is designed with two reactors operated in series. ${ }^{9}$ In this system concept, one reactor is extracting oxygen from the regolith at steadystate conditions, while the second reactor is dumping the spent regolith, filling with fresh regolith, recuperating energy, and then heating to operating temperature. For the conditions modeled here, the two dual-chamber reactors combined would require $6.1 \mathrm{~kW}(5.1 \mathrm{~kW}$ plus $1.0 \mathrm{~kW})$ of energy and the two single-chamber reactors would require

American Institute of Aeronautics and Astronautics 
$5.1 \mathrm{~kW}(4.3 \mathrm{~kW}$ plus $0.8 \mathrm{~kW}$ ). In this scenario, the dual-chamber concept would require 20 percent more power than the single chamber concept in spite of the benefit of being able to pre-heat the incoming regolith to higher temperatures. In addition, the dual chamber concept would be heavier and more complex in requiring a second regolith transfer for every batch.

Considering that during operations on the lunar surface there will be no convective losses to the environment, the energy balance was repeated assuming only radiative losses during heat-up and steady-state operation. In this case, while the energy loss during heat-up is still greater for the dual-chamber than the single-chamber design, the benefit of starting at significantly higher temperature for the regolith and the chamber walls results in similar total energy requirements. The model predicts that both the dual-chamber and single-chamber designs require $3.8 \mathrm{~kW}$ for continual operation $(2.8 \mathrm{~kW}$ heat-up plus $1.0 \mathrm{~kW}$ for steady-state processing for dual chamber, $3.0 \mathrm{~kW}$ plus $0.8 \mathrm{~kW}$ for the single chamber). As previously mentioned, this initial energy balance was performed assuming a 1-hour heatup cycle. Previous analysis of the effects of batch reaction time on total oxygen yield per batch showed an overall system energy benefit from longer processing times (heat-up cycle times are assumed the same as processing times in a two-reactor system). ${ }^{10}$ In the parametric study in Ref. 10, the knee in the energy curve as a function of processing time occurred between 2 and 3 hours. The energy balance using radiative losses only was repeated for heat-up times of 1.5 and 2 hours. The total energy required to heat-up the regolith and reactor structure is independent of time, but increased heat-up time will increase any losses to the environment. Therefore, as the larger surface area of the dual-chamber design results in higher radiative losses, the model predicts slightly higher energy requirements for the dual-chamber than the single-chamber reactor for longer heat-up times. These results are summarized in Table VI. As the radiation heat loss algorithms have not been validated with experimental data, and other portions of the thermal model have shown an error between 4 and 16 percent, there is still significant uncertainty in these predictions. However, in no permutation did the dual-chamber design concept show any

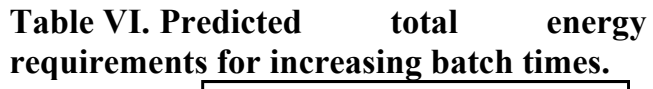
requirements for increasing batch times.

\begin{tabular}{|c|c|c|}
\cline { 2 - 3 } \multicolumn{1}{c|}{} & $\begin{array}{c}\text { Power for Heat-up and Steady- } \\
\text { State Processing, } \mathrm{kW}\end{array}$ \\
\hline $\begin{array}{c}\text { Heat-up Time, } \\
\mathrm{hr}\end{array}$ & Dual Chamber & Single Chamber \\
\hline 1.0 & 3.8 & 3.8 \\
1.5 & 3.1 & 2.9 \\
2.0 & 2.8 & 2.4 \\
\hline
\end{tabular}
clear energy savings over the single-chamber design.

\section{Conclusion}

Five tests were performed in a hydrogen reduction reactor with an annular outer chamber for heat recuperation. The two primary objectives were to compare methods for fluidization of the regolith simulant and to gather data for an energy balance comparison between the single and dual-chamber design concepts. A comparison of helium fluidization and vibrational fluidization during the recuperation phase in a single chamber indicated that the regolith and wall temperatures converged more quickly with vibrofluidization than helium gas fluidization. However, an analytical evaluation of the effective thermal conductivity showed a value of the same order of magnitude for both test cases indicating that the difference in rate of temperature convergence was not significant. Comparison of heatup data for helium fluidization and hydrogen fluidization at the same volumetric flow rates indicated the helium flow provided better mixing during heating than the hydrogen flow.

An analytical model was first validated against experimental data at the lower temperatures and then used to predict temperatures after a recuperation cycle for both the single and dual chambers assuming full operating temperatures of $1000{ }^{\circ} \mathrm{C}$ before the recuperation begins. The temperatures after the recuperation cycle were then used as inputs to a hydrogen reduction reactor model that calculates energy required during heat-up and energy losses during steady-state operations. This model showed that for the conditions tested here with significant convective losses, the dual chamber design requires 17 percent more energy for heat-up and 25 percent more energy during steady-state operations than the single chamber reactor for 1-hour batch times. Assuming that two reactors will be operating in parallel in an ISRU plant, one reacting while the other is heating, the dual reactor design requires 20 percent more energy for the two-reactor system than the single reactor. A similar energy balance was calculated for lunar conditions where only radiative heat loss to the environment will occur. In this case, the model predicts that the dual-chamber design requires the same energy as the single chamber for a 1-hour batch time. If batch times are increased to 2 hours as previous analysis recommended based on oxygen yield, the dual-chamber design is predicted to require 13 percent additional energy. While this predicted additional energy requirement is within the error bands of the model predictions, there was no case studied where the dual-chamber concept showed any clear energy benefit as was anticipated for this concept. Considering the additional mass and operational 
complexity of the dual-reactor concept, this concept does not appear to provide any overall benefit to the hydrogen reduction oxygen production plant system.

\section{Acknowledgments}

The authors greatly appreciate support from Mr. Dan Gotti in designing improvements in the flow path sealing and heater structural supports, and from Mr. John Doehne in implementing these design changes. The authors gratefully acknowledge the support of this work by the In-Situ Resource Utilization Project, which was part of the NASA Exploration Technology Development and Demonstration Program.

\section{References}

\footnotetext{
${ }^{1}$ Taylor, L. A., and Carrier, W.D. III, "Production of Oxygen on the Moon: Which Processes are Best and Why," AIAA
} Journal, 30, (12), 2858-2863 (1992).

${ }^{2}$ Altenberg, B. H., Franklin, H. A., and Jones, C. H., "Thermodynamics of Lunar Ilmenite Reduction," in Proceedings of the XXIV Lunar and Planetary Science Conference, Lunar and Planetary Institute, Houston, TX 1993, pp. 27-28.

${ }^{3}$ McKay, D. S., and Allen, C. C., "Hydrogen Reduction of Lunar Materials for Oxygen Extraction on the Moon," AIAA Paper No. 96-0488, AIAA Aerospace Sciences Meeting, January 1996.

${ }^{4}$ Linne, D.L., Kleinhenz, J.E., Hedge, U.G., and Gotti, D.J., "Investigation of Heat Recuperation in a Concentric Hydrogen Reduction Reactor," $49^{\text {th }}$ AIAA Aerospace Sciences Meeting, January 2011, AIAA 2011-610.

${ }^{5}$ Nayagam, V. and Sacksteder, K. R., "A Vibrofluidized Reactor for Resource Extraction from Lunar Regolith," in proceedings of Space Technology and Applications International Forum (STAIF-2006), edited by M. El-Genk, AIP Conference Proceedings, New York, 2006.

${ }^{6}$ Yuan, Z-G., and Kleinhenz, J.E., "Gas Phase Pressure Effects on the Apparent Thermal Conductivity of JSC1A Lunar Regolith Simulant," $41^{\text {st }}$ International Conference of Environmental Systems, April 2011, AIAA-2011-5138.

${ }^{7}$ Hegde, U. and Gokoglu, S., "Hydrogen Reduction of Lunar Regolith Simulants for Oxygen Production," $49^{\text {th }} A I A A$ Aerospace Sciences Meeting, January 2011, AIAA 2011-608.

8“2010 ASME Boiler and Pressure Vessel Code,” Volume II, Sec. VIII, Div. 1, Appendix 2.

${ }^{9}$ Linne, D.L., Gokoglu, S., Hegde, U.G., Balasubramaniam, R., and Santiago-Maldonado, E., "Component and System Sensitivity Considerations for Design of a Lunar ISRU Oxygen Production Plant," $47^{\text {th }}$ AIAA Aerospace Sciences Meeting, January 2009, AIAA-2009-1391.

${ }^{10}$ Linne, D.L., "Employing ISRU Models to Improve Hardware Design," $48^{\text {th }}$ AIAA Aerospace Sciences Meeting, January 2010, AIAA-2010-800. 